\title{
Complementos infinitivos num corpus de Português Clássico
}

\author{
Miguel Magalhães \\ Centro de Linguística da Universidade Nova de Lisboa \\ migmaglit@yahoo.com
}

\section{Infinitival complementation in Classic Portuguese}

\begin{abstract}
Resumo
Este trabalho pretende contribuir para uma melhor compreensão do infinitivo flexionado em português clássico. Em trabalhos como Martins (2006) e Fiéis e Madeira (2014) observou-se que a distribuição de infinitivo flexionado alterou-se do Português Antigo até ao Português Contemporâneo. Com base num corpus de um arquivo particular, proveniente do distrito de Braga, com textos notariais do século XVII (1650-1700), vamos descrever o uso do infinitivo flexionado em complementação infinitiva, mostrando as condiçóes que permitiram o seu alargamento a outros contextos do Português Contemporâneo.
\end{abstract}

\section{Palavras-chave}

Infinitivo flexionado, português clássico, complementos infinitivos, diacronia, sintaxe

\section{Sumário}

1. Objetivo. 2. Enquadramento teórico. 3. Constituição do corpus. 4. Levantamento das ocorrências. 5. Verbos ECM, fazer-Infinitivo e estruturas de controlo. 6. Primeiras conclusōes.

\begin{abstract}
This paper aims to contribute to a better understanding of inflected infinitive in Classic Portuguese. In works such as Martins (2006) and Fiéis \& Madeira (2014), it can be observed that the distribution of inflected infinitive changes from Old to Modern Portuguese. Based on a corpus from an archive located in the Braga district, with notarial texts from the xvii century (1650-1700), we will describe the use of the inflected infinitive in infinitival complementation during this period, assessing the conditions that allowed its widening to other contexts in Modern Portuguese.
\end{abstract}

Keywords

Inflected infinitive, classic Portuguese, infinitival complementation, diachrony, syntax

Summary

1. Objective. 2. Theoretical background. 3. Corpus of analysis. 4. Data analysis. 5. ECM constructions, faire-infinitive and control verbs. 6 . First conclusions. 


\section{Objetivo}

Este trabalho tem como objetivo descrever algumas estruturas de complementação infinitiva em português clássico $(\mathrm{PCl})$. Para isso, partimos da análise dos contextos em que ocorre o infinitivo flexionado (InfFlex) e, de acordo com os resultados alcançados, iremos observar os complementos infinitivos num corpus constituído para esse efeito. O ponto de partida desta análise justifica-se pelo facto de o InfFlex ser uma opção gramatical que apenas ocorre em português, galego e sardo. $\mathrm{Na}$ primeira secção deste trabalho, vamos fazer o levantamento das ocorrências do InfFlex de acordo com as conclusões já alcançadas em bibliografia específica. Esta primeira secção irá dar conta das ocorrências mas também de algumas ausências e irá introduzir o levantamento de domínios infinitivos como complemento de verbos causativos e perceptivos em estruturas de controlo, mais especificamente com verbos ECM e em construções fazer-infinitivo.

Serão também apresentadas algumas análises existentes em trabalhos sobre o InfFlex em estados mais antigos da língua, nomeadamente os trabalhos de Martins (sobretudo 2004 e posteriores) e o estudo e sistematização de Fiéis \& Madeira (2014) sobre a diacronia do InfFlex no português; na secção 2, apresentaremos a constituição do corpus de análise e a metodologia de seleção de dados; na secção 3, analisaremos os dados extraídos do corpus e apresentaremos uma reflexão teórica relativamente aos contextos estudados; e, finalmente, na secção 4, apresentaremos as conclusões.

\section{Enquadramento teórico}

Em trabalhos como Martins (2006) e Fiéis \& Madeira (2014), observamos que a distribuição do InfFlex alterou-se desde o Português Antigo (PA) até ao Português Europeu Contemporâneo (PEC). Algumas estruturas atestadas no PA (como as orações independentes com valor imperativo/optativo e coordenadas com conjuntivo) desaparecem no PCl. Outras emergem e mantêm-se até ao PEC (orações complemento de verbos declarativos, epistémicos, perceptivos e de controlo de objecto); e outras surgem em $\mathrm{PCl}$ mas não se mantêm até ao $\mathrm{PEC} \mathrm{(construções} \mathrm{com} \mathrm{verbos}$ aspectuais e de controlo de objeto). E que pode ser resumido no quadro 1.

Tal como está referido em Fiéis \& Madeira (2014), o InfFlex é uma opção gramatical que, nas línguas românicas contemporâneas, apenas ocorre em português, galego e sardo, embora com propriedades diferentes entre si.

A diacronia mostra que esta era uma opção disponível desde o PA, mas em contextos diferentes do PEC. Em PA surge associado, por exemplo, a domínios independentes de caráter imperativo/optativo, em alternância com o conjuntivo, o 
que não é possível em PEC. Segundo Martins (2006) e Fiéis \& Madeira (2014), estes domínios independentes começam a desaparecer por volta do séc. XVI à medida que começam a ocorrer como complementos de verbos causativos e perceptivos, associados a outras propriedades que começam a ocorrer também neste momento (nomeadamente a possibilidade de negação e de ocorrência de clíticos no domínio infinitivo).

\begin{tabular}{|c|c|c|}
\hline PA & PCl & PEC \\
\hline $\begin{array}{l}\text { Orações independentes com valor imperativo/ } \\
\text { optativo e coordenadas com conjuntivo }\end{array}$ & $x$ & $x$ \\
\hline $\begin{array}{l}\text { Orações complemento adverbiais introduzidas } \\
\text { por preposição (ou locuçôes prepositivas) }\end{array}$ & $\checkmark$ & $\checkmark$ \\
\hline Orações de sujeito & $\checkmark$ & $\checkmark$ \\
\hline Orações coordenadas com infinitivo impessoal & $\checkmark$ & $\checkmark$ \\
\hline$x$ & $\begin{array}{l}\text { Construções com verbos aspetuais e de controlo } \\
\text { de sujeito (com e sem coordenação) }\end{array}$ & $x$ \\
\hline$x$ & $\begin{array}{l}\text { Orações complemento de verbos declarativos, } \\
\text { epistémicos, perceitivos, de controlo de objeto } \\
\text { e factivos }\end{array}$ & $\checkmark$ \\
\hline
\end{tabular}

\section{QUADRO 1. DIACRONIA DO INFINITIVO FLEXIONADO A PARTIR} DE FIÉIS E MADEIRA (2014)

Em PA ocorre ainda em orações introduzidas pela conjunção copulativa $e$, e em orações coordenadas (alternando orações conjuntivas com orações de infinitivo não flexionado). Finalmente, podem encontrar-se ocorrências em orações introduzidas por preposições (adverbiais e complementos de adjetivos), e também em orações de sujeito e em complementos de verbos. Estes contextos, ao contrário dos domínios independentes que ocorriam em PA, como já referimos, não desaparecem em PCl.

Em relação a outros contextos possíveis em PEC tais como complementos de verbos epistémicos, factivos, controlo de objeto, das orações predicativas, comparativas e completivas de nome e de adjetivo, não existem dados suficientes sobre a sua origem.

\section{Constituição do corpus}

Para perceber a evolução destas formas, uma vez que os estudos anteriores incidem particularmente no PA, pretendemos averiguar a sua evolução num período mais tardio. Para esse efeito, decidimos constituir um corpus com documentos notariais uma vez que estudos anteriores baseavam-se sobretudo em textos literários. 
Deste modo, foi constituído um corpus com cerca de 10 textos notariais (cartas de venda, prazo, doação, entre outros) da $2^{\text {a }}$ metade do séc. XVII (1650 a 1700). Os documentos são provenientes de um arquivo particular e foram, na sua maioria, produzidos no distrito de Braga, no Norte de Portugal. Lembramos que este é um corpus de documentos notariais, geograficamente localizado, e que pretende acrescentar dados aos estudos sobre o InfFlex neste período e não fazer uma descrição do PCl.

Fez-se depois, com o auxílio de um programa de concordâncias, o levantamento das ocorrências do InfFlex e das construções com verbos de controlo, ECM e fazer-infinitivo, e procedeu-se à sua análise.

\section{Levantamento das ocorrências}

Em relação às ocorrências do InfFlex, em domínios independentes com valor imperativo/optativo e orações coordenadas com conjuntivo, confirma-se a sua ausência em PCl, tal como constatam Martins (2006) e Fiéis \& Madeira (2014).

Comparando o InfFlex em PA e PCl, mantêm-se em contextos que já ocorriam em PA como as orações complemento e adverbiais, introduzidas por preposições ou locuções prepositivas tanto causais como finais, como podemos ver nos exemplos seguintes:

Causais:

1. as ditas (...) rogarã asinase por ellas por ellas serem mulheres e nã saberem asinar (CG-7, 1694)

2. em razam de serem molheres doncellas de calidade por nom poderem hoo? acignar (CG-13, 1678)

Finais:

3. e acabadas as tres uidas deste prazo ficara uaguo liure e desembarguado [f10] desembarguado ao dito colegio como couza sua propria que hee contadas? as bem feitorias que nelle ouuer pera o darem e emprazarem a quem lhes parecer e mais for de dreito e iustiça (CG-13, 1678)

4. e lloguo alj por elles ditos reuerendos padres foj dito que pera efeito de fazerem prazo aellas sobreditas maria de souza e uentura machada se fes uedoria da ditta quinta da granja (CG-13, 1678)

É também atestado em orações coordenadas com infinitivo impessoal como no exemplo seguinte: 
5. e por serem uezinhos e parentes e escuzar as ditas duvidas e malquezias? e demandas se vierã a compor todos pella maneira seguinte (CG-7, 1674)

Não foram, no entanto, encontradas ocorrências em orações de sujeito.

Em relação a contextos surgidos no $\mathrm{PCl}$, de acordo com o levantamento feito por Fiéis \& Madeira (2014), o InfFlex pode ocorrer noutros contextos que não foram encontrados neste corpus, a saber: coordenado com um DP (pronomes demonstrativos, pronomes pessoais, artigos, quantificadores, elementos-QU ou por um elemento vazio); introduzido por um determinante; orações comparativas e predicativas e complementos de nomes. $\mathrm{O}$ mesmo ocorre com os contextos específicos do $\mathrm{PCl}$ (que não ocorriam em PA e que desapareceram em PEC) como são as construções com verbos aspetuais e de controlo de sujeito (com e sem coordenação).

Por outro lado, é também neste período que o InfFlex surge em contextos que se mantiveram em PEC como são os casos das orações complemento de verbos declarativos (6), epistémicos (7), controlo de objeto (8) ou percetivos (este último não atestado).

6. os quoais comfecaraõ elles uendedores terem ja em sj recebidos em moeda corente deste rejno sem quebra nem demonuisam alguma dos quoais diceraõ elles uendedores dauaõ ao comprador e a seus eerdeiros por quites e livres e desobrigados doie $\mathrm{p}[\mathrm{ar}] \mathrm{a}$ todo sempre $(\mathrm{CG}-12,1692)$

7. e todas partes $[+]$ testemunhas sam pesoas que $[\mathrm{eu}+]$ tabaliam conheco serem os mesmos e elles reconhecidos hũns dos outros eu? estacio ca[1dei+]ra da ueiga taballiã que $[\mathrm{o}+][\mathrm{es}+]$ creuy $(\mathrm{CG}-7,1674)$

8. foi dito que elles a fazer este instromento de contrato bom e de pas pera sempre obreiguauã suas pesoas e todos seus bens moveis e de rais auidos e por auer e tercos de suas almas a numqua emcontrar nem empedir este instromento e troqua e concerto pera sempre e numqua ho reuoguarem parte nem em todo pera sempre por si nem por outras pesoas (CG-7, 1674)

O exemplo (9) mostra ainda uma contrução onde ocorre a subida do sujeito do InfFlex para a posição de sujeito da frase passiva, que não é possivel em PEC:

9. apareserom maria de souza loba e uentura machada solteiras moradoras na quinta da granja da freiguezia de santo andre de uilla nune deste concelho de cabeseiras de basto, pessoas por mim tabaliam bem conhecidas serem as proprias que se nomeiam e lloguo alj por elles ditos reuerendos padres foj dito que pera efeito de fazerem prazo aellas sobreditas maria de souza e uentura machada se fes uedoria da ditta quinta da granja (CG-13,1678)

Sendo o InfFlex selecionado pelo verbo conhecer. 


\section{Verbos ECM, fazer-infinitivo e estrututras de controlo}

Se atendermos a aspetos quantitativos, o uso do InfFlex, neste corpus, é mais comum em orações adverbiais introduzidas por preposição, sendo o uso em estruturas de complementação pouco produtivo. Não são encontrados, por exemplo, InfFlex em complementos de verbos causativos e perceptivos, contextos que surgiram em $\mathrm{PCl}$ e que se mantiveram em PEC. Trata-se de uma construção que, de acordo com os trabalhos já citados, tornam-se comuns neste estado da língua. A ausência destas construções neste corpus levou-nos a analisar as construções com verbos causativos (não ocorrem verbos perceptivos neste corpus) para tentar perceber se existe algum factor que possa explicar a ausência destas estruturas num momento da língua em que deveriam ser mais comuns.

Recordamos, muito brevemente, que as construções com verbos causativos e perceptivos ocorrem sobretudo com verbos de Marcação Excepcional de Caso (ECM) e construções de fazer-infinitivo (União de Orações).

Embora estas estruturas estivessem disponíveis desde o PA, estas tinham características diferentes, em relação ao PEC, que não cabe neste trabalho especificar. No entanto, como Martins (2004 e sucessivos) demonstra, o infinitivo dependente de verbos ECM torna-se comum, de forma clara, a partir do séc. XVI, como já referimos anteriormente. Relembramos também (remetendo para as mesmas referências) que o InfFlex como complemento de verbos causativos e perceptivos é uma opção do PEC mas não se encontra atestada em PA e que o desaparecimento das orações infinitivas independentes começa a ocorrer à medida que as estruturas ECM se tornam mais comuns.

Segundo Martins (2006) existem três elementos que revelam o processo de desgramaticalização dos verbos ECM e de controlo e elevação: a emergência do InfFlex que passa a estar em variação com o infinitivo simples; a legitimação da negação predicativa das orações infinitivas selecionadas e, finalmente, a opção pela cliticização no interior da oração infinitiva em estruturas com verbos matriz potenciadores de subida do clítico.

Recupero, a este propósito, os exemplos (5) e (8). No exemplo (5) encontramos uma oração adverbial introduzida por uma preposição, em que o InfFlex está coordenado com um infinitivo simples. Enquanto no exemplo (8), a construção de controlo de objecto, exibe também uma estrutura coordenada com infinitivo simples, já atestada em PA.

5. e por serem uezinhos e parentes e escuzar as ditas duvidas e malquezias? e demandas se vierã a compor todos pella maneira seguinte (CG-7, 1674)

8. foi dito que elles a fazer este instromento de contrato bom e de pas pera sempre obreiguauã suas pesoas e todos seus bens moveis e de rais auidos e por auer e tercos de suas almas a numqua emcontrar nem empedir este ins- 
tromento e troqua e concerto pera sempre e numqua ho reuoguarem parte nem em todo pera sempre por si nem por outras pesoas (CG-7, 1674)

O exemplo (8) mostra como, em estruturas coordenadas de orações infinitivas dependentes de um verbo finito, o argumento causado (o DP controlado pelo verbo superior) é estruturalmente o sujeito do verbo infinitivo, embora receba caso acusativo do verbo que o controla. Repare-se que tal só é possível porque as especificações de pessoa e número do verbo superior e do InfFlex são idênticas.

Se considerarmos o exemplo (10), observamos que um processo parecido ocorre em construções fazer-infinitivo:

10. e mandarã a mim tabaliã fazer este publiquo instromento nesta nota (CG$7,1674)$

Mas neste exemplo, é atribuído caso dativo ao sujeito do verbo infinitivo através da preposição $a$ e que é reforçada pela presença do pronome pessoal oblíquo que lhe sucede.

Mais uma vez necessitamos de observar as ocorrências destas estruturas de controlo em termos quantitativos: neste corpus, observamos uma preferência clara pelo uso de construções fazer-infinitivo uma vez que não ocorrem construções com verbos ECM. Deste modo, encontramos neste corpus as seguintes estruturas:

(a) Construções fazer-infinitivo com dativização do sujeito

10. e mandarã a mim tabaliã $\mathrm{fa}[\mathrm{f} 6 \mathrm{v}]$ fazer este publiquo instromento nesta nota (CG-7, 1674)

11. e por asi serem de parte e parte contentes mandaraõ a mim tabaliaõ fazer este publico instromento (CG-15, 1692)

12. e mandarão a mim tabaliaõ e escriuaõ do tõbo e prazos delle fazer este publico estroimento de nouo emprazamẽto ẽ meu liuro de notas (CG-1, 1656)

(b) Construções fazer-infinitivo

13. poderaõ elles ssenhorio? mandar sitar demandar dobrigar aele cazeiro emprazante (CG-1, 1656)

14. poderam elles senhorios mandar citar e obriguar a ellas cazeiras emprazantes (CG-13, 1678)

(c) Construções fazer-infinitivo com atribuição de caso acusativo ao objeto direto

11. e delle mandaraõ dar hũ treslado pera o cartorio do collégio (CG-1, 1656) 
(d) Construções fazer-infinitivo com movimento do clítico para o verbo superior:

12. e as faraó pouoar e cultiuar fazendo nellas todas as bemfeitorias que fazer puderẽ $(\mathrm{CG}-1,1656)$

13. [...] a fes escreuer $(\mathrm{CG}-8,1699)$

14. e elles o prometeraõ fazer asi (CG-15, 1692)

Não irei fazer uma análise detalhada destas estruturas porque não está no âmbito deste trabalho, mas parece-me importante refletir sobre se a sua ocorrência está relacionada ou não com a ausência do InfFlex nas estruturas de complementação dos verbos causativos e perceptivos. Ana Maria Martins (2015), baseada em dados e análises sólidos, tem proposto que as estruturas com verbos ECM derivam das construções fazer-infinitivo, apesar de ambas coocorrerem no PA. De acordo com trabalhos recentes feitos com o PEC (citados em Martins 2015), apesar das estruturas com verbos ECM serem preferidas no PEC padrão escrito, as construções fazer-infinitivo estão distribuídas por todo o território, enquanto as construções com verbos ECM estão restritas a áreas específicas. Isto, por si só, não explica a ausência do InfFlex como complemento de verbos causativos e perceptivos, uma vez que as estruturas ECM estavam disponíveis desde o PA, como já referimos. Mas se consideramos que tanto as construções com verbos ECM como o InfFlex tem em comum o facto das completivas não finitas constituírem domínios com sujeitos independentes (diferenciando-se no facto de nas ECM o sujeito receber caso acusativo, enquanto no InfFlex recebe caso nominativo), então é seguro considerar que a ausência das estruturas com verbos ECM está diretamente ligada à ausência de InfFlex como complemento de verbos causativos e perceptivos neste corpus.

\section{Primeiras conclusões}

A nossa análise teve como primeiro objetivo descrever algumas construções de complementação infinitiva num corpus de português clássico. Partindo do levantamento das ocorrências do InfFlex neste corpus, procuramos enquadrá-las na diacronia do InfFlex, mostrando as condições que permitiram o seu alargamento a um maior número de contextos em PEC. De acordo com a diacronia do InfFlex feita por Fiéis \& Madeira (2014), o InfFlex ocorre nas estruturas esperadas neste período da língua. $\mathrm{O}$ facto de não encontrarmos em alguns contextos, como complemento de verbos causativos e perceptivos, levou-nos a procurar nos verbos de Controlo, ECM e construções de fazer-infinitivo, pistas que pudessem clarificar esta ausência, uma vez que é nestas construções que eles ocorrem com mais frequência em PEC.

O levantamento que foi feito mostra-nos que relativamente a verbos de controlo, o InfFlex ocorria em coordenação com o infinitivo simples, tal como vimos no 
exemplo (8). Em relação a verbos ECM e construções fazer-infinitivo, as construções analisadas mostraram que neste corpus há uma preferência clara por construções fazer-infinitivo, não sendo encontrada nenhuma construção com verbos ECM. Esta ausência leva-nos a formular algumas interrogações sobre o comportamento das estruturas de controlo e a sua função nesta diacronia. E também se o facto de ser um corpus geográfica e tipologicamente restrito influencia estes resultados preliminares. Em trabalhos futuros esperamos fazer um levantamento dos verbos de controlo e as construções que originam e, inevitavelmente, ampliar o corpus de análise, dentro da mesma tipologia textual.

\section{REFERÊNCIAS BIBLIOGRÁFICAS}

Duarte, Inês / Anabela Gonçalves / Ana Lúcia Santos (2012): "Infinitivo flexionado, independência temporal e controlo", Textos Selecionados, XXVII Encontro Nacional da Associação Portuguesa de Linguística. Lisboa: APL, 217-234.

Fí́is, Alexandra / Ana Madeira (2014): "O infinitivo flexionado na diacronia do português”, em João Veloso et al. (orgs.), Textos selecionados. XXIX Encontro Nacional da Associação Portuguesa de Linguística, Porto: APL, 255-264.

Gonçalves, Anabela (1999): Predicados Complexos Verbais em Contextos de Infinitivo não Preposicionado do Português Europeu. Dissertação de doutoramento. Lisboa: Faculdade de Letras da Universidade de Lisboa.

Martins, Ana Maria (2004): "Ambiguidade estrutural e mudança linguística: A emergência do infinitivo flexionado nas orações complemento de verbos causativos e perceptivos", em Ana Maria Brito / Olívia Figueiredo / Clara Barros (orgs.), Linguística Histórica e História da Lingua Portuguesa. Actas do Encontro de Homenagem a Maria Helena Paiva. Porto: Secção de Linguística do Departamento de Estudos Portugueses e de Estudos Românicos da Faculdade de Letras da Universidade do Porto, 197-225.

Martins, Ana Maria (2006): "Aspects of Infinitival Constructions in the History of Portuguese”, em Randall Gess / Deborah Arteaga (eds.), Historical Romance Linguistics: Retrospective and Perspectives. Amsterdam / Philadelphia: John Benjamins, 327-355.

Martins, Ana Maria (2012): "Coordination, gapping, and the Portuguese inflected infinitive: The role os structural ambiguity in synthactic change”, em Dianne Jonas / John Whitman / Andrew Garrett (eds.), Grammatical Change: Origins, Nature, Outcomes. Oxford / New York: Oxford University Press, 274-291.

Martins, Ana Maria [2015]: "Infinitival complements of causative/perception verbs in a diachronic perspective”, em Anabela Gonçalves / Ana Lúcia Santos (eds.), Complement clauses in Portuguese: Syntax and Acquisition. Amsterdam: John Benjamins (no prelo). 